\title{
Proposta de uma cerâmica obtida por meio de geopolimerização de lodo de ETA calcinado
}

\section{(Proposal of a ceramic obtained by geopolymerization of calcined sludge from WTP)}

\author{
G. Z. B. Santos ${ }^{1 *}$, J. A. Melo Filho ${ }^{1}$, L. Manzato ${ }^{1}$ \\ ${ }^{1}$ Universidade Federal do Amazonas, Programa de Pós-Graduação em Engenharia Civil, \\ Av. Gen. Rodrigo Octávio Jordão Ramos 6200, 69080-005, Manaus, AM, Brasil
}

\begin{abstract}
Resumo
Neste estudo, pelo método de geopolimerização, produziu-se uma cerâmica alternativa utilizando como matéria-prima lodo de estação de tratamento de água (ETA). Primeiramente, esse resíduo foi seco, moído, peneirado e calcinado, sendo caracterizado antes e após tais procedimentos. Com o lodo de ETA devidamente calcinado, a $750{ }^{\circ} \mathrm{C}$ por $4 \mathrm{~h}$, produziu-se um geopolímero. Esse material, em estado endurecido, é semelhante a certos tipos de cerâmicas. Os corpos de prova geopoliméricos produzidos foram curados à temperatura ambiente durante 1, 7 e 28 dias. Após a cura, foram caracterizados por meio de difração de raios X, fluorescência de raios $\mathrm{X}$, microscopia eletrônica de varredura e resistência à compressão axial. Curado à temperatura ambiente, $\mathrm{o}$ geopolímero atingiu, em média, $20 \mathrm{MPa}$ em apenas 1 dia de idade e $60 \mathrm{MPa}$ aos 28 dias. Constatou-se, portanto, que lodos de ETA podem ser utilizados no desenvolvimento de materiais cerâmicos de elevada resistência mecânica. Com base nos resultados obtidos, sugere-se que o geopolímero produzido possa ser aprimorado e incorporado pelas indústrias de cerâmicas estruturais. O processo adotado, além do baixo consumo energético, mostrou-se uma excelente opção para a destinação de lodos de ETA. Palavras-chave: geopolímero, cerâmica, destinação de lodo de ETA, calcinação.
\end{abstract}

\begin{abstract}
In this study, by the geopolymerization method, an alternative ceramic was produced using as raw material sludge from water treatment plant (WTP). First, the WTP sludge was dried, milled, sieved and calcined, being characterized before and after such procedures. With the WTP sludge properly calcined, at $750^{\circ} \mathrm{C}$ for $4 \mathrm{~h}$, a geopolymer was produced. The geopolymeric specimens produced was cured at room temperature for 1, 7 and 28 days. After curing, it was characterized by means of X-ray diffraction, $X$-ray fluorescence, scanning electron microscopy and axial compression strength. Cured at room temperature, the geopolymer reached, on average, $20 \mathrm{MPa}$ in only 1 day of age and $60 \mathrm{MPa}$ at 28 days. It was verified, therefore, that WTP sludge can be used in the development of ceramic materials of high mechanical resistance. Based on the results obtained, it is suggested that the geopolymer produced can be improved and incorporated by the ceramics industries. The process adopted, besides the low energy consumption, proved to be an excellent option for the destination of WTP sludge.
\end{abstract}

Keywords: geopolymer, ceramic, WTP sludge disposal, calcination.

\section{INTRODUÇÃO}

No final da década de 1970, devido a diversos incêndios na França, o cientista Davidovits buscou desenvolver artefatos plásticos mais resistentes ao fogo e, para tanto, utilizou como matéria-prima aluminossilicatos naturais abundantes na crosta terrestre $[1,2]$. Desse modo, criou um novo material de base geológica, classificado como polímero inorgânico, ao qual denominou geopolímero $[1,2]$. Na síntese do primeiro material, $1 \mathrm{~kg}$ de argila caulinítica calcinada (precursor) e $300 \mathrm{~g}$ de solução alcalina de hidróxido de sódio (ativador) foram misturados e mantidos dentro de um saco plástico por cerca de $1 \mathrm{~h}$.

*gessicaz@hotmail.com
Tais componentes reagiram entre si e a mistura resultante originou o primeiro geopolímero [3]. De modo geral, geopolímeros em estado fresco apresentam propriedades de aglomerantes. Já em estado endurecido, comportamse como cerâmicas. Alguns estudos sugerem que as pirâmides do Egito foram construídas empregando-se uma tecnologia similar à geopolimerização [4]. Partindo desse pressuposto, os componentes das pirâmides seriam rochas artificiais sintetizadas in loco. Ao longo dos anos a tecnologia dos geopolímeros foi aprimorada e esses passaram a ter uma variedade de aplicações. Geopolímeros podem ser utilizados pelas indústrias da construção civil, de cerâmicas refratárias, aeronáutica, automobilística, nuclear, dentre outras [1-3, 5]. Apesar da versatilidade, possuem pouco espaço no mercado, 
sobretudo na construção civil que necessita de materiais alternativos, frente à atual escassez de recursos naturais.

Diversas barreiras obstam tanto a produção quanto a competividade de geopolímeros em relação aos produtos convencionais [5-9]. As matérias-primas de origem natural mais utilizadas na produção desses materiais são o caulim e o metacaulim (ou caulim calcinado) [3]. No Brasil existem grandes reservas do referido mineral, mas essa abundância não é uma realidade mundial. Nos países importadores de metacaulim para fins de geopolimerização, o preço do produto final se torna caro [6]. O álcali utilizado como ativador, dependendo do tipo e da quantidade, também pode elevar o custo produtivo de geopolímeros [7]. A carência de normas específicas e a dificuldade dessa tecnologia adequar-se aos padrões de conformidade estabelecidos aos produtos amplamente comercializados, análogos aos geopolímeros, são alguns dos impasses de ordem regulamentar enfrentados [6]. Dentre os pontos positivos, geopolímeros merecem reconhecimento por suas características de elevada resistência mecânica e durabilidade em ambientes agressivos [1, 2, 5-8]. Além disso, apresentam excelentes propriedades tecnológicas mesmo quando produzidos à base de resíduos $[5,7,8]$. Nesse sentido, visando à cadeia produtiva geopolimérica, verifica-se a importância de identificar e caracterizar os mais diferentes tipos de subprodutos industriais, uma vez que, se constituídos de sílica, alumina e/ou cálcio, poderão ser utilizados como matéria-prima. Tem-se então um grande desafio, pois a maioria dos resíduos apresenta composição heterogênea e geração sazonal [5-8]. Nesse contexto, a tecnologia geopolimérica tem se destacado por incorporar uma diversidade de resíduos [7], por vezes incompatíveis com a composição de certos materiais de construção convencionais como o cimento Portland [6].

Alguns estudos recentes demonstraram que lodos gerados no processo de tratamento de água, destinada ao abastecimento público, podem ser utilizados como matéria-prima geopolimérica, seja como agregado [10-12] ou como precursor [13-17]. Nas estações de tratamento de água (ETAs) do tipo convencional, a água bruta, captada geralmente de mananciais superficiais, necessita ser submetida a uma série de processos físicoquímicos para se tornar potável. Em um dos processos, visando a remoção de cor e turbidez, adiciona-se à água bruta reagentes químicos coagulantes, comumente sais de ferro e/ou de alumínio. O sulfato de alumínio $\left[\mathrm{Al}_{2}\left(\mathrm{SO}_{4}\right)_{3}\right]$ é o coagulante mais utilizado por ser mais acessível e de baixo custo [18]. Com a adição do coagulante, as partículas presentes na água bruta aglomeram-se e decantam, originando um resíduo bastante comum: o lodo de ETA. O lodo de sulfato de alumínio é um líquido não newtoniano, gelatinoso, com um percentual de sólidos constituído de hidróxidos de alumínio, partículas inorgânicas, coloides de cor e outros resíduos orgânicos [18]. Suas características variam em função da água bruta, dos processos realizados na ETA e dos produtos químicos aplicados [18]. Segundo os responsáveis, somente em uma ETA, das 4 operantes na cidade de Manaus, são geradas diariamente até 12 toneladas desse subproduto industrial. No Brasil, lodos de ETA são frequentemente lançados em cursos d'água $[17,18]$, de forma irregular.

Lodos de ETA têm sido objeto de diversas pesquisas, na maioria das vezes, direcionadas ao aproveitamento desse resíduo pela indústria cerâmica [19-32]. De modo geral, problemas de queda de resistência mecânica, aumento da absorção de água, porosidade, fissuras e trincas são relacionados à incorporação de lodo de ETA em massa cerâmica [20, 22-25, 29, 30, 32]. Esse resíduo é bastante úmido, contém elevado teor de sais de alumínio e/ou ferro, além de matéria orgânica, os quais reagem de forma negativa na estrutura de artefatos cerâmicos, comprometendo sua qualidade. Diante dessas limitações, verifica-se a importância de se beneficiar o lodo de ETA antes de sua utilização. Existem métodos de tratamento térmico, como a calcinação, que podem solucionar, por exemplo, os problemas decorrentes de excesso de umidade e matéria orgânica. Quanto a geopolímeros, em uma pesquisa, na qual utilizou-se lodo de ETA como precursor parcial, sem o emprego de calcinação, observouse no produto resultante a diminuição da resistência, seguida de aumento de porosidade e permeabilidade [17]. Esse material, contendo $15 \%$ de lodo em substituição ao metacaulim, atingiu $25 \mathrm{MPa}$ de resistência à compressão aos 28 dias [17]. Em outro estudo [13], um geopolímero foi preparado utilizando lodo de ETA como precursor, em substituição a $10 \%$ de cinzas volantes, sendo que, nesse caso, o resíduo apresentava duas diferenças relevantes: era constituído de elevado teor de cálcio e foi calcinado a $900{ }^{\circ} \mathrm{C}$ por $1 \mathrm{~h}$. No referido estudo, verificou-se que o produto geopolimérico alcançou resistência à compressão $>50 \mathrm{MPa}$ aos 28 dias [13]. Em outra pesquisa, um lodo de ETA calcinado a $800{ }^{\circ} \mathrm{C}$ por $1 \mathrm{~h}$, com elevado teor de sílica e alumina, foi empregado como precursor total na síntese de geopolímeros [14]. Aos 28 dias, esse material apresentou cerca de $9 \mathrm{MPa}$ de resistência à compressão. Apesar das diferenças tanto metodológicas quanto da composição química dos componentes geopoliméricos, em ambos os trabalhos o lodo de ETA foi utilizado como precursor parcial ou integral. Porém, no exemplo [17], o lodo não foi calcinado, o que provavelmente ocasionou os efeitos adversos relatados. No estudo [14], o tempo de calcinação de $1 \mathrm{~h}$ não foi suficiente para que o resíduo desenvolvesse mais reatividade [3]. O presente trabalho é parte de uma pesquisa voltada à produção de geopolímeros à base de lodo de ETA [33], e teve como objetivo propor o aproveitamento desse tipo de resíduo como matéria-prima de um novo material, obtido por meio de geopolimerização, para usos análogos aos de cerâmicas estruturais.

\section{MATERIAIS E MÉTODOS}

Materiais: como precursor geopolimérico foi utilizado 
Tabela I - Composição química (\% em massa) dos componentes do geopolímero.

[Table I - Chemical composition (wt\%) of components of the geopolymer.]

\begin{tabular}{lccccccccccc}
\hline Material & $\mathrm{SiO}_{2}$ & $\mathrm{Al}_{2} \mathrm{O}_{3}$ & $\mathrm{Fe}_{2} \mathrm{O}_{3}$ & $\mathrm{~K}_{2} \mathrm{O}$ & $\mathrm{TiO}_{2}$ & $\mathrm{MgO}$ & $\mathrm{CaO}$ & $\mathrm{P}_{2} \mathrm{O}_{5}$ & $\mathrm{SO}_{3}$ & $\mathrm{Cl}$ & Outros \\
\hline Lodo seco & 39,94 & 37,62 & 14,08 & 2,45 & 1,57 & 0,66 & 0,71 & 0,92 & 1,01 & 0,50 & 0,54 \\
Lodo calcinado & 40,44 & 42,19 & 11,30 & 2,22 & 1,29 & 0,91 & 0,58 & 0,66 & - & - & 0,41 \\
CP III 40 RS & 22,26 & 6,45 & 3,18 & 0,92 & 0,40 & 3,50 & 59,44 & 0,28 & 2,96 & - & 0,61 \\
Potassa & - & - & - & 99,62 & - & - & - & 0,22 & - & - & 0,16 \\
Sílica industrial & 87,37 & 0,60 & 3,00 & 2,71 & - & 2,63 & 0,72 & 0,38 & 1,17 & - & 1,42 \\
\hline
\end{tabular}

lodo cedido pela estação de tratamento de água do Programa Águas para Manaus - PROAMA. Esse resíduo foi devidamente beneficiado por meio de secagem em estufa, a $110{ }^{\circ} \mathrm{C}$ por $8 \mathrm{~h}$; moagem em moinho de bolas cerâmico por $2 \mathrm{~h}$; peneiramento em peneira da ABNT $\mathrm{n}^{\circ}$ 100 (abertura da malha de $150 \mu \mathrm{m}$ ); e calcinação em forno mufla a $750{ }^{\circ} \mathrm{C}$ por $4 \mathrm{~h}$. Como fonte adicional de cálcio, empregou-se o cimento Portland - CP III 40 RS, Mizu, à base de escória de alto forno. Uma areia comercial da região, de granulometria média, retida em peneira da $\mathrm{ABNT} \mathrm{n}^{\circ} 50$ (abertura da malha de $300 \mu \mathrm{m}$ ), foi utilizada como agregado. $\mathrm{O}$ meio empregado para proporcionar a dissolução dos componentes secos foi uma solução de silicato de potássio, composta de hidróxido de potássio (Potassa Cáustica, Mawin), sílica industrial (Microsilica Grade 920 ASTM, Elkem) e água proveniente da rede de abastecimento de Manaus. Na Tabela I consta a composição química do lodo, antes e após a calcinação, e dos demais componentes do geopolímero, com exceção da areia e da água que dispensam tal análise.

Caracterização do lodo: o tamanho e a distribuição das partículas, a composição química, a mineralogia e o comportamento térmico do lodo foram respectivamente obtidos, antes e após a calcinação, por meio de granulometria a laser (granulômetro, Malvern, Mastersizer 2000), fluorescência de raios X - FRX (espectrômetro, PANalytical, Epsilon $3^{\mathrm{x}}$ ), difração de raios X - DRX [difratômetro, PANalytical, Empyrean, com goniômetro teta/teta e tubo de raios $\mathrm{X}$ cerâmico de anodo de $\mathrm{Cu}(\mathrm{K} \alpha 1$ 1,5406 $\AA$ )] e termogravimetria - TG (TA Instruments, SDT Q600, taxa de aquecimento de 10 ${ }^{\circ} \mathrm{C} / \mathrm{min}$, até $1000{ }^{\circ} \mathrm{C}$, e com fluxo de gás nitrogênio 5.0 de $30 \mathrm{~mL} / \mathrm{min}$ ). As medidas de DRX foram obtidas sob as seguintes condições instrumentais: voltagem $40 \mathrm{kV}$; corrente $40 \mathrm{~mA}$; ângulo de varredura $10-100^{\circ}(2 \theta)$; passo de $0,02^{\circ}(2 \theta)$. A identificação das fases cristalinas foi

Tabela II - Dosagem dos materiais (\% em massa) utilizados na produção do geopolímero.

[Table II - Materials content (wt\%) used in the production of geopolymer.]

\begin{tabular}{cccccc}
\hline \multicolumn{2}{c}{ Precursor } & Agregado & \multicolumn{3}{c}{ Ativador } \\
Lodo & $\begin{array}{c}\text { CP III } \\
40 \mathrm{RS}\end{array}$ & Areia & Potassa & Água & Sílica \\
\hline $38 \%$ & $8 \%$ & $10 \%$ & $14 \%$ & $17 \%$ & $13 \%$ \\
\hline
\end{tabular}

realizada utilizando o programa X'Pert HighScore Plus, comparando o difratograma obtido com padrões do banco de dados do ICDD PDF-2 Release 2003.

Dosagem e preparação do geopolímero: a dosagem do geopolímero foi estabelecida de acordo com as razões molares entre todos os seus componentes, com base na composição elementar do lodo calcinado e seguindo, com adaptações, algumas patentes de domínio público [34-37]. Na Tabela I pode-se verificar que o resíduo estudado mesmo antes da calcinação já se mostrava uma excelente fonte de sílica e alumina. Após a calcinação, a soma desses mesmos componentes passou a representar mais de $80 \%$ da composição do lodo. Contudo, a razão sílica/alumina do lodo calcinado era inferior a 1. Em materiais geopoliméricos, quanto maior a razão sílica/ alumina mais refinadas são as propriedades do produto obtido $[1,2]$. Nesse trabalho, para elevar a razão sílica/ alumina da composição do geopolímero, adicionou-se sílica industrial no álcali ativador. Em um estudo [13], cujo lodo era composto majoritariamente de cálcio e magnésio, verificou-se que o geopolímero preparado com $10 \%$ de lodo calcinado em substituição ao precursor (cinzas volantes), alcançou resistência à compressão $>50$ $\mathrm{MPa}$ aos 28 dias. Outro geopolímero [14], no qual utilizouse como precursor apenas lodo de ETA calcinado, rico em sílica e alumina, sem uma fonte adicional de cálcio, atingiu apenas $9 \mathrm{MPa}$ de resistência à compressão aos 28 dias. Como o percentual de cálcio do lodo calcinado utilizado no presente trabalho era baixo, o que poderia refletir na resistência mecânica do material dele resultante, introduziu-se na composição geopolimérica, como fonte adicional de cálcio, um cimento à base de escória de alto forno, visando aprimorar a resistência mecânica e acelerar o tempo de pega do geopolímero produzido $[2,34]$. Os percentuais, em massa, de cada componente empregado na preparação do produto final constam na Tabela II.

Buscando-se obter maior reatividade e melhor dissolução dos precursores, a solução de silicato de potássio foi preparada com $24 \mathrm{~h}$ de antecedência à produção do geopolímero. Com o auxílio de um misturador mecânico, o ativador e os componentes secos, já devidamente homogeneizados (lodo de ETA calcinado, o cimento Portland e a areia), foram misturados. Após a mistura, procedeu-se a moldagem de corpos de prova de $41 \mathrm{~mm}$ de diâmetro e $82 \mathrm{~mm}$ de altura. Esses, decorridas $24 \mathrm{~h}$, foram desmoldados e colocados dentro de sacos 


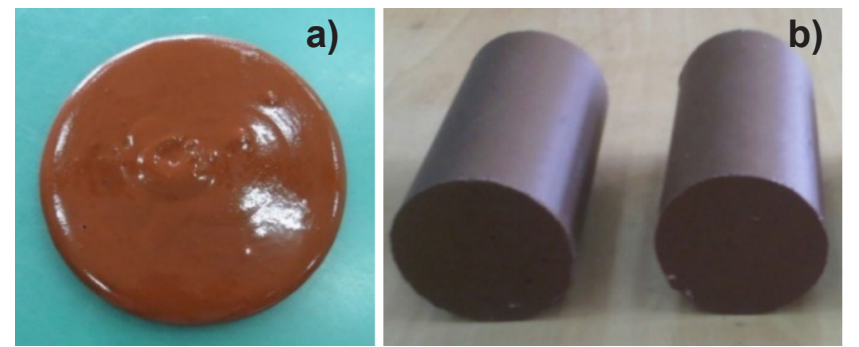

Figura 1: Fotografias do geopolímero em estado fresco (a) e endurecido (b).

[Figure 1: Photographs of the geopolymer in fresh (a) and hardened (b) condition.]

plásticos, para evitar a perda de água, e deixados em uma câmara à temperatura ambiente até o dia da realização dos ensaios mecânicos. A sinterização não foi necessária, pois o material curou rapidamente à temperatura ambiente. $\mathrm{O}$ aspecto do geopolímero em estado fresco e endurecido pode ser visto, respectivamente, nas Figs. 1a e $1 \mathrm{~b}$.

Caracterização do geopolímero: a composição química e mineralógica do geopolímero foi determinada por meio de FRX e DRX, respectivamente, sob as mesmas condições que o lodo. A morfologia da superfície de fratura do geopolímero aos 7 dias de cura foi analisada por meio de microscopia eletrônica de varredura - MEV (FEI, Quanta 250). A caracterização mecânica do geopolímero foi realizada por meio de ensaio à compressão axial, nas idades de 1, 7 e 28 dias, utilizando-se um equipamento de ensaios mecânicos (Emic, DL30000N). Para cada ensaio de resistência, foram moldados 4 corpos de prova, seguindo-se, com adaptações, a norma brasileira aplicável ao cimento Portland [38].

\section{RESULTADOS E DISCUSSÃO}

\section{Caracterização do lodo}

Na Fig. 2 pode-se observar as mudanças físicoquímicas que aconteceram no lodo após a calcinação. Analisando o lodo calcinado, Fig. 2b, verifica-se visualmente a grande perda de massa que ocorreu no processo. A cor escura do lodo se deve às características da água bruta, captada do Rio Negro, que possui elevado teor de matéria orgânica dissolvida [39]. Considerando que a coloração do lodo mudou completamente, concluiu-se que o processo de calcinação foi eficiente, no que concerne à combustão de matéria orgânica. Com o auxílio de análises termogravimétricas, apresentadas na Fig. 3a, foi possível avaliar mais detalhadamente as perdas de massa e os eventos térmicos ocorridos. O lodo submetido às análises térmicas foi analisado sob duas condições: após a secagem em estufa, a $110^{\circ} \mathrm{C}$ por $8 \mathrm{~h}$, e após a calcinação, a 750 ${ }^{\circ} \mathrm{C}$ por $4 \mathrm{~h}$. Portanto, a água livre já havia sido removida em ambos os casos. Ainda assim, provavelmente devido ao armazenamento, o lodo seco adquiriu umidade, pois um pico referente à perda de água livre $[20,22,25,29$, 31], situado entre 25 e $110^{\circ} \mathrm{C}$, pôde ser visto na derivada

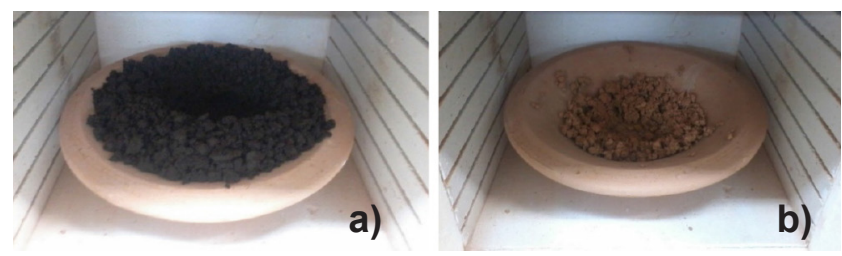

Figura 2: Fotografias do lodo antes (a) e após (b) a calcinação. [Figure 2: Photographs of the sludge before (a) and after (b) calcination.]
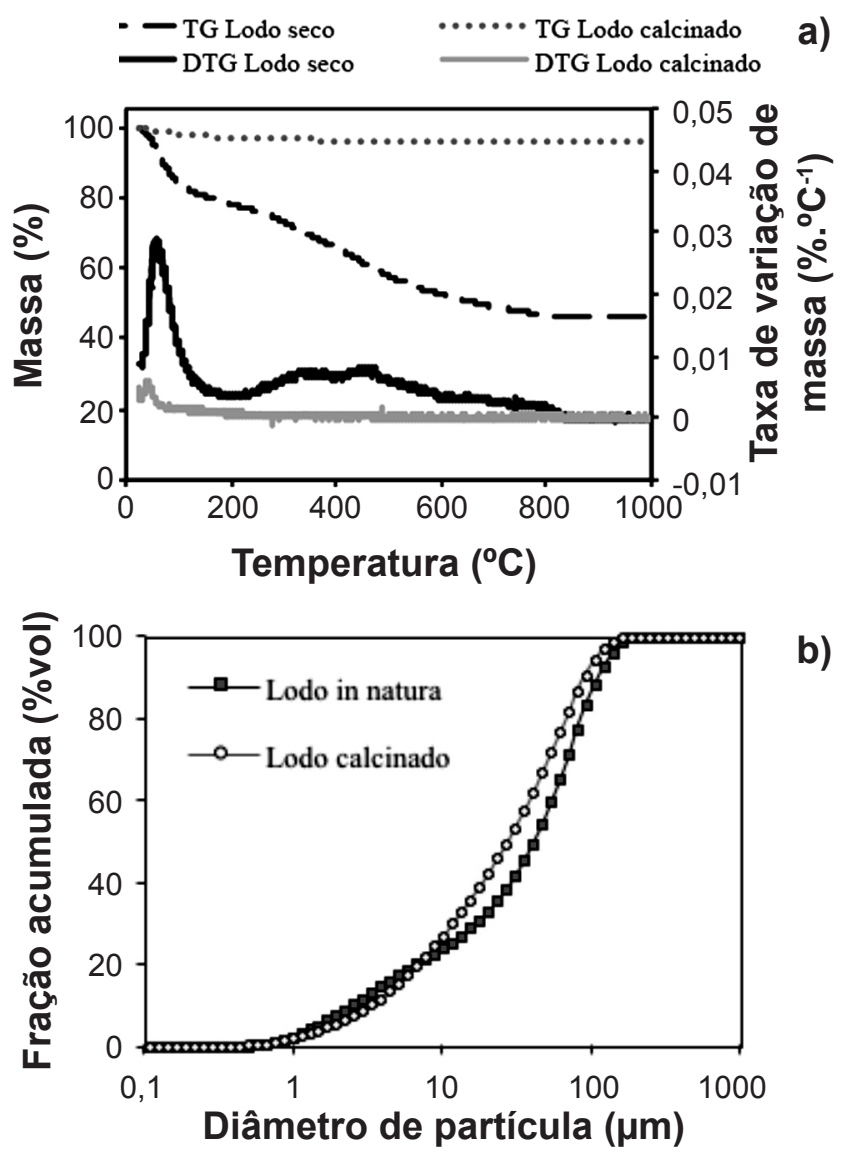

b)

Figura 3: Curvas de análise termogravimétrica, TG, e derivada, DTG (a), e de distribuição de tamanho de partículas (b) do lodo de ETA, antes (in natura) e após a calcinação.

[Figure 3: Curves of thermogravimetric analysis, TG, and derivative, DTG (a), and of particle size distribution (b) of the WTP sludge, before (in natura) and after calcination.]

(DTG) de seu respectivo termograma, Fig. 3a. As demais perdas de massa exibidas pelo lodo seco foram associadas principalmente à combustão de matéria orgânica e desidroxilação de minerais [20, 22, 25, 29, 31]. Quanto ao lodo calcinado, foi observada apenas uma perda de umidade mínima.

$\mathrm{Na}$ Fig. 3b constam os resultados das análises granulométricas do lodo, antes e após a calcinação. Tanto em cerâmicas convencionais [40] quanto em geopolímeros [5, 7, 13], o tamanho e a distribuição das partículas da matéria-prima exercem bastante influência nas propriedades tecnológicas do produto 
final. No caso de geopolímeros, quanto mais finas são as partículas, mais reativas e, consequentemente, o material produzido apresenta propriedades mais refinadas $[5,7,13]$. Em ensaios normalmente utilizados para caracterizar solos, verificou-se que as partículas de um lodo de ETA específico, quanto à textura, enquadravamse no limiar entre siltes e argilas, segundo a escala da ABNT pertinente [41]. O lodo utilizado nesse trabalho em estado in natura era composto de partículas cujos diâmetros $\mathrm{D}_{10}, \mathrm{D}_{50}$ e $\mathrm{D}_{90}$ apresentavam valores de 2,44, 40,30 e $109,77 \mu \mathrm{m}$, respectivamente. Após a secagem em estufa, essas partículas se aglutinaram, fazendo-se necessários procedimentos de moagem e peneiramento. Já devidamente seco, moído e peneirado, o lodo foi calcinado e passou a exibir diâmetros $\mathrm{D}_{10}, \mathrm{D}_{50}$ e $\mathrm{D}_{90}$ nos valores de 3,23, 26,74 e 89,07 $\mu \mathrm{m}$, respectivamente. Ao observar que a maioria das partículas do lodo calcinado apresentava diâmetro médio $<100 \mu \mathrm{m}$, enquadrando-se como siltes e argilas, de acordo com a norma brasileira [42], considerou-se os processos de moagem e peneirameto satisfatórios.

As análises químicas do lodo, exibidas na Tabela I, mostraram que esse resíduo, por sua composição elevada de sílica e alumina, tem potencial de uso como matériaprima geopolimérica. As análises de DRX, apresentadas na Fig. $4 a$, revelaram que as fases cristalinas presentes no lodo de ETA seco eram o quartzo $\alpha$ (01-089-8936), o rutilo (01-088-1174), a caulinita (01-089-6538) e a cristobalita leve (01-076-0938). Após a calcinação, verificou-se o surgimento de uma fase de muscovita (01-080-0743), enquanto o quartzo $\alpha$ (01-089-8937) e o rutilo (00-0340180) foram detectados com padrões cristalográficos diferentes dos exibidos pelo lodo seco. A caulinita sofreu desidroxilação, não sendo mais identificada no lodo calcinado. Apesar das análises químicas (Tabela I) assinalarem a presença de elevados percentuais de óxidos de alumínio e ferro na composição do lodo, esses não foram detectados por meio de DRX, provavelmente, por ambos os óxidos se encontrarem em fase amorfa.

\section{Caracterização do geopolímero}

Na Tabela III são apresentados os resultados da análise química do geopolímero. Com uma razão sílica/alumina entre 1 e 2, o geopolímero criado nessa pesquisa é indicado para aplicações como cerâmicas, materiais de proteção contra o fogo, cimentos e concretos [2]. No difratograma de raios X referente ao geopolímero, Fig. 4a, observouse uma banda típica de materiais geopoliméricos [1], situada entre $25 \mathrm{e} 35^{\circ}$. Apenas três fases cristalinas foram detectadas na composição do geopolímero, sendo uma de quartzo $\alpha$ (01-089-8936), outra de quartzo leve (01-0850460) e um tipo de zeólita composta de silicato de potássio, sódio, cálcio, alumínio, ferro, magnésio e titânio (01-0896217). Na zeólita, verificou-se uma combinação de todos os óxidos encontrados na análise química, inclusive os
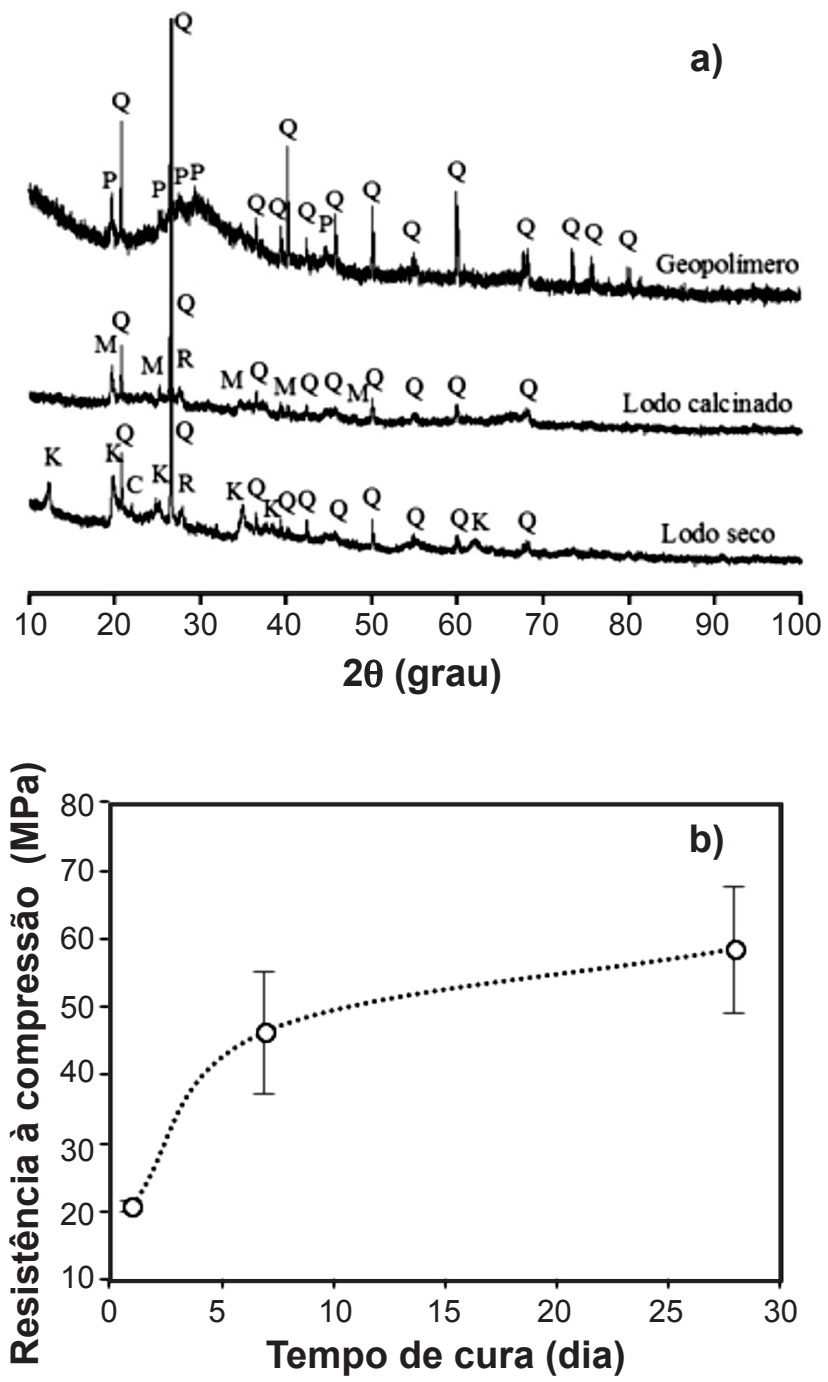

Figura 4: Difratogramas de raios $\mathrm{X}$ do lodo e do geopolímero [Q - quartzo, K - caulinita, C - cristobalita, R - rutilo, M muscovita, $\mathrm{P}$ - zeólita (silicato de potássio sódio cálcio alumínio ferro magnésio titânio)] (a), e resistência à compressão do geopolímero em diferentes idades (b).

[Figure 4: X-ray diffraction patterns of the sludge and geopolymer [ $Q$ - quartz, $K$ - kaolinite, $C$-cristobalite, $R$-rutile, $M$ - muscovite, $P$ - zeolite (potassium sodium calcium aluminum iron magnesium titanium silicate)] (a), and compressive strength of the geopolymer (b).]

Tabela III - Composição química (\% em massa) do geopolímero.

[Table III - Chemical composition (wt\%) of geopolymer.]

\begin{tabular}{ccccccccccc}
\hline $\mathrm{SiO}_{2}$ & $\mathrm{Al}_{2} \mathrm{O}_{3}$ & $\mathrm{Fe}_{2} \mathrm{O}_{3}$ & $\mathrm{~K}_{2} \mathrm{O}$ & $\mathrm{TiO}_{2}$ & $\mathrm{MgO}$ & $\mathrm{CaO}$ & $\mathrm{P}_{2} \mathrm{O}_{5}$ & $\mathrm{SO}_{3}$ & $\mathrm{Cl}$ & Outros \\
\hline 40,41 & 19,89 & 8,16 & 20,46 & 0,85 & 1,18 & 7,58 & 0,49 & 0,32 & 0,10 & 0,56 \\
\hline
\end{tabular}


de ferro e alumínio, que não haviam sido detectados pela análise de DRX dos lodos. Esses resultados corroboram a literatura, pois geopolímeros são análogos a certas zeólitas [1], mas diferenciam-se dessas por apresentarem estrutura que varia de amorfa à semicristalina. As fases de quartzo identificadas são decorrentes tanto da fração de areia presente no lodo quanto da adicionada como agregado. A areia, por ser um material inerte, não sofreu geopolimerização.

Na Fig. 4b constam os resultados de resistência à compressão das amostras geopoliméricas. Em apenas 1 dia, o geopolímero apresentou resistência mecânica média $>20$ MPa. Tendo como referência a norma brasileira [43], os valores apresentados pelo material produzido à base de lodo superaram valores estabelecidos para cimento Portland de alta resistência inicial: $14 \mathrm{MPa}$ a um dia de idade e 34 $\mathrm{MPa}$ aos 7 dias. Tal produto é utilizado, por exemplo, no preparo de blocos para pavimentação, postes, tubos e lajes. $\mathrm{O}$ alcance desses resultados se deve à interação de vários fatores. A calcinação do lodo é um deles, pois materiais calcinados normalmente exibem maior reatividade durante a geopolimerização $[5,13]$. Do mesmo modo, esses resultados podem ser atribuídos à finura do lodo, pois materiais finamente moídos são mais facilmente dissolvidos durante a geopolimerização, contribuindo para a elevada resistência mecânica $[13,44]$. O CP composto de escória, utilizado como fonte de cálcio, também cooperou $[2,34]$. Adicionalmente, o teor de óxido de alumínio contribuiu para a elevada resistência do geopolímero em idades inicias, corroborando a literatura [15, 44]. Esses resultados são relevantes, pois evidenciaram que os produtos obtidos por meio da geopolimerização de lodo de ETA calcinado não necessitam de sinterização, uma vez que curados à temperatura ambiente exibiram elevada resistência mecânica em apenas 1 dia. Sem a sinterização, a calcinação da matéria-prima (lodo), a $750{ }^{\circ} \mathrm{C}$ por $4 \mathrm{~h}$, se torna viável, possibilitando a fabricação de um produto de qualidade superior, em relação àqueles fabricados com lodo bruto. Com base nesses resultados, é possível inferir que os efeitos adversos que a incorporação de lodo de ETA in natura tem causado em diferentes produtos [20, $22-25,29,30,32]$ se devem ao elevado teor de umidade e matéria orgânica geralmente presentes nesses resíduos.

$\mathrm{Na}$ literatura, observou-se que certos tipos de geopolímeros, cuja composição química é próxima à do material desenvolvido no presente estudo, quando submetidos a tratamentos térmicos em elevada temperatura tornaram-se cerâmicas refratárias do tipo leucita $[45$, 46]. Sendo assim, sugere-se que o lodo de ETA estudado pode ser utilizado, por meio de geopolimerização, tanto na fabricação de cerâmicas estruturais, por sua elevada resistência mecânica, quanto na produção de artefatos refratários, uma vez que a sua composição química é próxima à de certos geopolímeros refratários.

$\mathrm{Na}$ Fig. 5, constam as micrografias da superfície de fratura de fragmentos do geopolímero. Essa análise revelou que o material produzido aos 7 dias exibia uma matriz densa, porém com poros e microfissuras. Os poros podem estar relacionados à pouca trabalhabilidade e pega imediata do geopolímero. Nesse trabalho, não se fez uso de retardador de pega, pois não se tinha conhecimento de que o material viria a apresentar pega imediata. Por conta disso, durante a moldagem dos corpos de prova, foi impraticável a agitação prolongada do geopolímero em estado fresco, o que impediu a completa retirada de bolhas de ar nele retidas. Tanto a pouca trabalhabilidade como as microfissuras podem estar relacionadas à composição granulométrica do lodo e da areia utilizada como agregado. Em ensaios preliminares, não inclusos nesse estudo, quando o geopolímero foi preparado sem agregado, observou-se maior incidência de microfissuras,
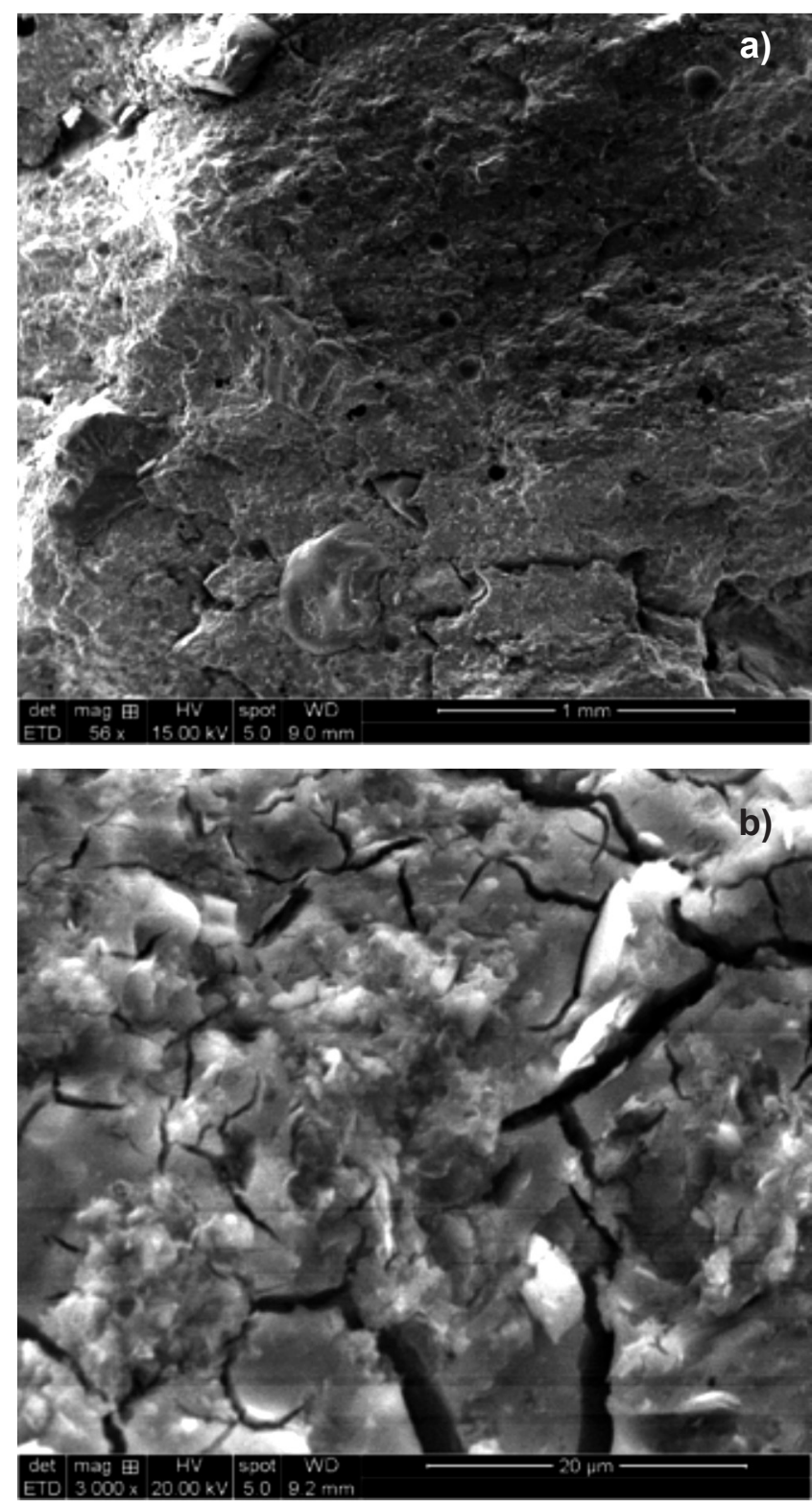

Figura 5: Micrografias obtidas por microscopia eletrônica de varredura do geopolímero aos 7 dias de cura.

[Figure 5: SEM micrographs of the geopolymer after 7 days of cure.] 
além de pouquíssima trabalhabilidade. Sabe-se que uma composição granulométrica adequada, com a presença de materiais não plásticos, como a areia, pode melhorar a trabalhabilidade da massa, bem como a qualidade do produto final [40]. Nessa pesquisa, a areia utilizada como agregado foi adicionada à composição do geopolímero com a finalidade de amenizar os defeitos identificados nas primeiras amostras geopoliméricas preparadas. Além desses defeitos, também se verificou no geopolímero o surgimento de eflorescência quando esse era exposto à umidade.

Em oposição aos defeitos relatados, a Fig. 4b evidencia que nos ensaios de resistência à compressão, aos 7 dias a resistência do geopolímero foi em média 46 $\mathrm{MPa}$, enquanto aos 28 dias alcançou aproximadamente $60 \mathrm{MPa}$. Verifica-se, portanto, que a resistência mecânica do geopolímero aumentou com o decorrer do tempo de cura. Considerando que seria inviável um material com a integridade estrutural comprometida apresentar resultados de resistência à compressão elevados, admite-se que, como ocorre em peças cerâmicas durante a sinterização [28], o crescimento e empacotamento das partículas densificaram o geopolímero ao longo dos dias, diminuindo os defeitos morfológicos encontrados em idades iniciais. Além do mais, em amostras envelhecidas nenhuma microfissura foi observada, o que é condizente com a literatura, pois geopolímeros com elevada resistência mecânica geralmente apresentam propriedades de estabilidade e durabilidade [7]. Defeitos como microfissuras e eflorescência são comuns em produtos geopoliméricos em estágio inicial de cura. No caso das microfissuras, podem ser solucionadas, como nas cerâmicas convencionais [40], adequando-se a granulometria tanto do precursor (lodo), quanto do agregado (areia). Considerando que as microfissuras são associadas à necessidade de areia e de finos, e que a eflorescência é resultado do excesso de álcali no geopolímero [47], esses resultados indicam que o material necessita de maiores percentuais de areia, de granulometria variada, e menores percentuais de álcali. Dos componentes geopoliméricos, a areia é o mais barato enquanto o álcali é o mais caro. Sendo assim, do ponto vista econômico, com a melhoria da formulação, possivelmente poderá ser produzido um material de qualidade e, ao mesmo tempo, mais barato.

Em relação ao seu homólogo [33], que foi produzido com lodo calcinado a $750{ }^{\circ} \mathrm{C}$ por $6 \mathrm{~h}$, o geopolímero desenvolvido no presente trabalho apresentou diferença significativa apenas no quesito resistência mecânica. No ensaio de resistência à compressão, além de exibirem valores superiores em todas as idades avaliadas, os corpos de prova do geopolímero homólogo [33] mostraram-se mais homogêneos, com resultados muito próximos e menor desvio padrão. Em todas as demais caracterizações não se observaram diferenças entre os dois geopolímeros. Considerando o bom desempenho mecânico do produto apresentado nesse estudo, concluiu-se que o lodo de ETA avaliado, calcinado a $750{ }^{\circ} \mathrm{C}$, seja por 4 ou $6 \mathrm{~h}$, é uma matéria-prima adequada para a produção de geopolímeros. Contudo, para o lodo calcinado a $750{ }^{\circ} \mathrm{C}$ por $4 \mathrm{~h}$ o custo produtivo é inferior.

\section{CONCLUSÕES}

Os resultados obtidos foram úteis para assinalar a necessidade de se adicionar à mistura geopolimérica um retardador de pega, diminuir o teor de álcali e aumentar a quantidade de areia e finos, a fim de se obter um produto de boa qualidade, apto a ser inserido na indústria cerâmica. Uma avaliação geral de todas as caracterizações realizadas comprova que a geopolimerização de lodo de ETA é uma opção interessante para a destinação desse resíduo. Geopolímeros ainda não são normatizados no Brasil, mas suas características em estado endurecido, muito próximas às de certos produtos cerâmicos, permitem que se faça uso de normas brasileiras aplicadas aos mesmos. Conclui-se que o lodo de ETA estudado, se devidamente calcinado, por meio de geopolimerização, pode ser utilizado na produção de materiais cerâmicos de elevada resistência mecânica. Acredita-se que os custos com a calcinação do lodo e a aquisição de álcali para a ativação alcalina possam ser compensados. Como a matéria-prima é um resíduo, a compra de aluminossilicatos naturais é dispensável. Portanto, a proposta apresentada, além de técnica e economicamente viável, mostrou-se uma excelente opção para a destinação de lodos de ETA.

\section{REFERÊNCIAS}

[1] J. Davidovits, J. Therm. Anal. 37 (1991)1633.

[2] J. Davidovits, Geopolymer 2002 Conf., Melbourne, Australia (2002).

[3] J. Davidovits, in Mater. Today (2016) <http://www. materialstoday.com/polymers-soft-materials/features/ geopolymers-natural-and-synthetic-metakaolin/>, ac. 24/08/2017.

[4] J. Davidovits, G. Demortier, in Proc. $2^{\text {nd }}$ Int. Conf. Geopolymere '99, Saint-Quentin, France (1999) 327.

[5] K. Komnitsas, D. Zaharaki, Miner. Eng. 20 (2007) 1261.

[6] P. Duxson, J.L. Provis, G.C. Lukey, J.S.J. Van Deventer, Cem. Concr. Res. 37 (2007) 1590.

[7] P.W. Ken, M. Ramli, C.C. Ban, Constr. Build. Mater. 77 (2015) 370.

[8] P.N. Lemougna, K. Wang, Q. Tang, U.C. Melo, X. Cui, Ceram. Inter. 42 (2016) 15142.

[9] P. Duxson, J.S.J. Van Deventer, in Geopolymers: structure, processing, properties and industrial applications, Eds.: J.L. Provis, J.S.J. Van Deventer, Woodhead Publ., Cambridge (2009) 379.

[10] S. Horpibulsuk, C. Suksiripattanapong, W. Samingthong, R. Rachan, A. Arulrajah, J. Mater. Civ. Eng. 28 (2015) 4015078.

[11] C. Suksiripattanapong, S. Horpibulsuk, S. Boongrasan, A. Udomchai, A. Chinkulkijniwat, A. 
Arulrajah, Constr. Build. Mater. 94 (2015) 807.

[12] C. Suksiripattanapong, S. Horpibulsuk, P. Chanprasert, P. Sukmak, A. Arulrajah, Constr. Build. Mater. 82 (2015) 20.

[13] X. Guo, H. Shi, W. Dick, J. Am. Ceram. Soc. 93, 1 (2010) 272.

[14] N. Waijarean, S. Asavapisit, K. Sombatsompop, Constr. Build. Mater. 50 (2014) 486.

[15] E. Nimwinya, W. Arjharn, S. Horpibulsuk, T. PhooNgernkham, A. Poowancum, J. Clean. Prod. 119 (2016) 128 .

[16] F. Messina, C. Ferone, A. Molino, G. Roviello, F. Colangelo, B. Molino, R. Cioffi, Constr. Build. Mater. 133 (2017) 14.

[17] R.H. Geraldo, L.F.R. Fernandes, G. Camarini, J. Clean. Prod. 149 (2017) 146.

[18] C.A. Richter, Tratamento de lodos de estações de tratamento de água, Edgard Blücher, S. Paulo (2001).

[19] E.M.S. Oliveira, S.Q. Machado, J.N.F. Holanda, Cerâmica 50 (2004) 324.

[20] S.R. Teixeira, S.A. de Souza, N.R. de Souza, P. Aléssio, G.T.A. Santos, Cerâmica 52 (2006) 215.

[21] E.M.S. Oliveira, J.N.F. Holanda, Cerâmica 54 (2008) 167.

[22] S.N. Monteiro, J. Alexandre, J.I. Margem, R. Sánchez, C.M.F. Vieira, Constr. Build. Mater. 22 (2008) 1281.

[23] L.C.C. Paixão, H.N. Yoshimura, D.C.R. Espinosa, J.A.S. Tenorio, Cerâmica 54 (2008) 63.

[24] C.M.F. Vieira, J.I. Margem, S.N. Monteiro, Rev. Matéria 13, 2 (2008) 275.

[25] J.P.D. Vitorino, S.N. Monteiro, C.M.F. Vieira, Cerâmica 55 (2009) 385.

[26] K-Y. Chiang, P-H. Chou, C-R. Hua, K-L. Chien, C. Cheeseman, J. Hazard. Mater. 171 (2009) 76.

[27] R. Tartari, N. Díaz-Mora, A.N. Módenes, S.A. Pianaro, Cerâmica 57 (2011) 288.

[28] R. Tartari, A.N. Módenes, S.A. Pianaro, N. Díaz-Mora, Cerâmica 57 (2011) 387.

[29] S.R. Teixeira, G.T. A. Santos, A.E. Souza, P. Alessio, S.A. Souza, N.R. Souza, Appl. Clay Sci. 53 (2011) 561.
[30] L.P. Rodrigues, J.N.F. Holanda, Cerâmica 59 (2013) 551.

[31] O. Kizinievic, R. Zurauskiene, V. Kizinievic, R. Zurauskas, Constr. Build. Mater. 41 (2013) 464.

[32] T. Ahmad, K. Ahmad, M. Alam, J. Clean. Prod. 124 (2016) 1.

[33] G.Z.B. Santos, “Argamassa geopolimérica à base de lodo de estação de tratamento de água calcinado”, Diss. Mestr., UFAM (2016).

[34] J. Davidovits, J.L. Sawyer, "Early high-strength mineral polymer", United States Patent 4,509,985 (1985).

[35] J. Davidovits, "Mineral polymers and methods of making them", United States Patent 4,349,386 (1982).

[36] J. Davidovits, M. Davidovics, N. Davidovits, "Process for obtaining a geopolymeric alumino-silicate and products thus obtained", United States Patent 5,342,595 (1994).

[37] J. Davidovits, R. Davidovits, "Poly(sialate-disiloxo)based geopolymeric cement and production method thereof", United States Patent US2005/0172860A1 (2005).

[38] Ass. Bras. Normas Técn., "Cimento Portland determinação da resistência à compressão”, NBR 7215, ABNT, Rio de Janeiro (1996).

[39] E. Franzinelli, Rev. Bras. Geociênc. 41, 4 (2011) 587.

[40] S. Pracidelli, F.G. Melchiades, Cerâm. Ind. 2, 1/2 (1997) 31 .

[41] H.J.F. Sartori, M.S. Nunes, Anais $19^{\circ}$ Congr. Bras. Eng. Sanit. Amb., Foz do Iguaçu (1997) 1151.

[42] Ass. Bras. Normas Técn., "Rochas e solos terminologia”, NBR 6502, ABNT, Rio de Janeiro (1995).

[43] Ass. Bras. Normas Técn., "Cimento Portland de alta resistência inicial - especificação”, NBR 5733, ABNT, Rio de Janeiro (1991).

[44] L. Weng, K. Sagoe-Crentsil, T. Brown, S. Song, Mater. Sci. Eng. B 117 (2005)163.

[45] J.L. Bell, P.E. Driemeyer, W.M. Kriven, J. Am. Ceram. Soc. 92, 3 (2009) 607.

[46] P. He, D. Jia, S. Wang, J. Eur. Ceram. Soc. 33 (2013) 689.

[47] J.L. Provis, P. Duxson, J.S.J. Van Deventer, Adv. Pow. Technol. 21 (2010) 2.

(Rec. 26/08/2017, Rev. 01/10/2017, 06/11/2017, Ac. 23/11/2017) 